\title{
Title: Partial amniotic carbon dioxide insufflation for fetal surgery
}

Running title: $\mathrm{CO}_{2}$ amnio-insufflation and fetoscopy

Word Count: abstract: 129; Main text: 3679; Table count: 2; Figure count: 1

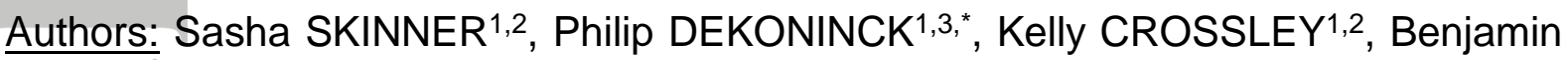
AMBERG $^{1,2}$, Jan DEPREST ${ }^{4,5,6}$, Stuart HOOPER ${ }^{1,2}$, Ryan HODGES ${ }^{1,3}$

Affiliations:

1The Ritchie Centre, Hudson Institute for Medical Research, Clayton, VIC, Australia ${ }^{2}$ Department of Obstetrics and Gynaecology, Monash University, Clayton, VIC,

Australia

${ }^{3}$ Perinatal Services Monash Health, Monash Medical Centre, Clayton, VIC, Australia ${ }^{4}$ Division of Woman and Child, Department of Obstetrics \& Gynaecology, University Hospitals Leuven, Belgium.

${ }^{5}$ Department of Development and Regeneration, Cluster Woman and Child, Group Biomedical Sciences, KU Leuven, Belgium

${ }^{6}$ Institute for Women's Health, University College London, London, UK

*Presently working at Department of Obstetrics and Gynaecology, Erasmus MC, Rotterdam, The Netherlands

Corresponding Author: Associate Professor Ryan Hodges, Program Director, Women's and Newborn; Director of Obstetrics, Monash Health, Monash Medical Centre, Clayton, VIC, Australia 3168. Telephone: +613 9594 5145, Fax: +6139594 5003, Email: $\underline{\text { Ryan.Hodges@monash.edu }}$

Disclosure statement: The author(s) report(s) no conflict of interest

Sources of Financial Support: This work was supported by the Monash Health 2018 Emerging Researcher Fellowship awarded to Dr Sasha Skinner. Professor Jan

This article has been accepted for publication and undergone full peer review but has not been through the copyediting, typesetting, pagination and proofreading process which may lead to differences between this version and the Version of Record. Please cite this article as doi: 10.1002/pd.5362 
Deprest is funded through an Innovative Engineering for Health award by the Wellcome Trust (WT101957), the Engineering and Physical Sciences Research Council (EPSRC) (NS/A000027/1) and the Great Ormond Street Hospital Charity fund.

\section{Bulleted statements}

What's already known about this topic?

- PACl causes fetal hypercapnia and acidosis in sheep

- Early case series of fetoscopic myelomeningocoele repair using PACl reported high rates of PPROM and preterm birth, however recent case series describe improved pregnancy outcomes.

- Limited clinical series using PACI do not show abnormal neurological development in operated fetuses

What does this study add?

- Comprehensive review of literature from animal and clinical studies relating to PACI

- Discuss possible mechanisms and effects of PACl insufflation pressure, duration, humidity and maternal hyperventilation on fetal physiology and wellbeing 


\section{Abstract}

Partial amniotic carbon dioxide insufflation (PACI) involves insufflating the amniotic sac with carbon dioxide $\left(\mathrm{CO}_{2}\right)$ and, in some cases, draining some of the amniotic fluid. The creation of a gaseous intra-amniotic compartment improves visualization, even in the presence of limited bleeding, and creates the work space required for complex fetoscopic procedures. Clinically, PACI is mostly used to perform fetoscopic myelomeningocoele (MMC) repair, enabling a minimally invasive alternative to open fetal surgery. However, evidence of the fetal safety of PACl is limited. Previous animal experiments in sheep demonstrate that PACI induces fetal hypercapnia and acidosis with largely unknown short and longer-term implications. In this review, we examine the literature for the physiological effects of intrauterine insufflation pressure, duration, humidity and the role of maternal hyperventilation on fetal physiology and wellbeing.

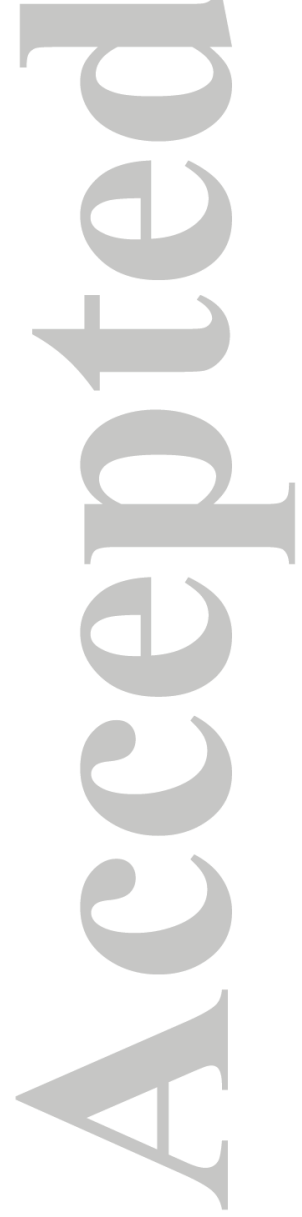




\section{Introduction}

One of the challenges of fetoscopic surgery is the confined liquid-filled intra-uterine environment, which limits visibility, fetal immobilization and maneuverability of surgical instruments. Partial amniotic carbon dioxide insufflation (PACl) was proposed to overcome these limitations by draining a portion of amniotic fluid and insufflating the uterus with $\mathrm{CO}_{2} .^{1,2}$ Gaseous uterine distension improves visualization, allows better control of bleeding and enables use of the required surgical tools in a more conducive workspace ${ }^{3,4}$. PACl thus enables complex fetoscopic surgeries, such as myelomeningocoele (MMC) repair. ${ }^{5-9}$ However, there are safety concerns about PACI as in sheep it causes severe fetal hypercapnia and acidosis. ${ }^{10-13}$ The impact of PACI at clinically relevant pressures and duration on utero-placental circulation, uterine membranes and the fetal brain are not well described. ${ }^{1,10-13}$ Furthermore, there is no consensus on optimal maternal ventilation targets during $\mathrm{PACl}$ to offset fetal hypercapnia. ${ }^{10-13}$ Given that antenatal MMC repair by hysterotomy is beneficial, there is much interest in optimizing this operation using fetoscopy to avoid maternal morbidity associated with hysterotomy. ${ }^{14}$ In this review, we summarize the available literature concerning $\mathrm{PACl}$, as scarcity of data and fundamentally different study designs prevent rigorous systematic review. We further discuss the physiological principles relevant to $\mathrm{CO}_{2}$ insufflation and define novel research questions relating to the clinical use of PACI.

\section{Fetal surgery for myelomeningocoele}

Myelomeningocoele (MMC) is characterized by a vertebral column defect that exposes the underlying spinal cord to the intra-uterine environment and allows cerebrospinal fluid leakage, resulting in prenatal hindbrain herniation, changes in ventricular size and 
progressive neurological impairment. ${ }^{15-19}$ The "Management of Myelomeningocoele Study" demonstrated that antenatal MMC repair via open fetal surgery improves neuromotor outcomes and reduces hindbrain herniation and postnatal shunt rate compared to postnatal repair. ${ }^{14}$ However, open fetal surgery is associated with high rates of premature delivery, significant maternal complications and implications for future pregnancies. ${ }^{14,20,21}$

Fetoscopic MMC repair using PACI was therefore proposed as a minimally invasive alternative to reduce preterm birth and maternal morbidity. However, initial experience resulted in high rates of PPROM, preterm delivery, pregnancy complications and perinatal death compared to open fetal surgery..$^{5,8,22}$ Additionally, animal studies demonstrating severe fetal hypercapnia and acidosis during PACI increased safety concerns for the developing fetus. ${ }^{10-13}$

On the other hand, recent clinical series report more promising maternal and fetal outcomes. ${ }^{9}$ A recent preliminary case series of three fetuses undergoing fetoscopic MMC repair using PACI suggests that fetal hypercapnia in humans may not be as severe as described in animal models. ${ }^{23}$ However, umbilical vein blood samples were collected after $\mathrm{PACl}$, during the recovery phase. Interestingly, the $\mathrm{pH}$ reduction was least in the fetus exposed to heated-humidified PACI. ${ }^{23}$ This could be explained by reduced fetal $\mathrm{CO}_{2}$ absorption due to lower $\mathrm{CO}_{2}$ solubility at higher temperatures and reduced $\mathrm{CO}_{2}$ partial pressures due to higher water vapor pressures. ${ }^{24}$

While case series report no perinatal deaths or adverse outcomes directly linked to $\mathrm{PACl}$, concerns remain for the potential of fetal neurological injury. ${ }^{5-9,25}$ Indeed, adverse neurological outcomes relating to $\mathrm{PACl}$ may be difficult to distinguish from other causes given multiple confounding factors that may contribute to neurologic disability in this patient group. This includes the natural history of MMC, success and 
timing of repair, duration of anesthesia and iatrogenic prematurity. Therefore, robust animal studies are required to thoroughly assess the independent neurological risk relating to $\mathrm{PACl}$ use.

Multiple procedure related factors could contribute to high PPROM rates following fetoscopic MMC repair, such as long operating times, dehydration, cooling and using multiple trocars. ${ }^{5-9,26}$ However, it is unclear whether PACl influences PPROM risk by prolonged $\mathrm{CO}_{2}$ exposure of the uterine membranes, insufflation pressure or gas temperature and humidity. ${ }^{5-8,14,22}$ Interestingly, lower PPROM rates have been reported when heated-humidified, low-pressure, low-flow PACl is used in an exteriorized uterus, permitting surgical closure of the fetal membranes. ${ }^{9}$

The debate concerning the optimal surgical approach for fetoscopic MMC repair is ongoing, as discussed in several recent papers on this subject, and is thus not the focus of this review. ${ }^{25,27-29}$ However, optimization of the PACI technique may also influence clinical outcomes and is potentially relevant to other surgeries, such as fetoscopic laser-coagulation. ${ }^{30}$

\section{Carbon dioxide physiology}

$\mathrm{CO}_{2}$ is a highly soluble by-product of aerobic cellular metabolism that rapidly diffuses from tissues into the blood (Figure 1). Approximately $65-70 \%$ of $\mathrm{CO}_{2}$ in blood reacts with water molecules within red blood cells to produce carbonic acid $\left(\mathrm{H}_{2} \mathrm{CO}_{3}\right)$, a reaction catalyzed by carbonic anhydrases (CA). ${ }^{31,32}$ Carbonic acid quickly dissociates into hydrogen ions $(\mathrm{H}+)$ and bicarbonate ions $\left(\mathrm{HCO}_{3}{ }^{-}\right) . \mathrm{H}+$ bind with deoxygenated hemoglobin and other proteins, whilst $\mathrm{HCO}_{3}^{-}$diffuses out the cell (Figure 1(a)). This is known as the carbonic acid-bicarbonate buffer system (equation below) whereby the reaction direction depends on substrate and product levels. 
$\mathrm{CO}_{2}+\mathrm{H}_{2} \mathrm{O} \leftrightarrow \mathrm{H}_{2} \mathrm{CO}_{3} \leftrightarrow \mathrm{HCO}_{3}{ }^{-}+\mathrm{H}^{+}$

Approximately $20-25 \%$ of $\mathrm{CO}_{2}$ binds directly to hemoglobin in red blood cells (Figure $1(b))$, while only $8-10 \%$ dissolves in plasma (Figure $1(c)$ ). Due to its high solubility, postnatally $\mathrm{CO}_{2}$ is efficiently eliminated from the pulmonary circulation during expiration. ${ }^{33}$ In healthy non-pregnant adults, alterations in pulmonary ventilation (rate and/or tidal volume) maintain an arterial $\mathrm{CO}_{2}$ pressure $\left(\mathrm{PaCO}_{2}\right)$ of $35-45 \mathrm{mmHg}$. Meanwhile, $\mathrm{H}^{+}$levels are controlled by binding to plasma proteins, renal $\mathrm{H}^{+}$excretion and $\mathrm{HCO}_{3}-$ reabsorption and $\mathrm{H}^{+} / \mathrm{HCO}_{3}^{-}$re-association following pulmonary $\mathrm{CO}_{2}$ elimination. Thus, $\mathrm{pH}$ is tightly regulated at $7.35-7.45$, which is essential for cellular function..$^{33}$

\section{Homeostatic response to hypercapnia and acidosis}

In adults

Hypercapnia refers to high blood partial pressure of $\mathrm{CO}_{2}\left(\mathrm{PaCO}_{2}\right)$, typically resulting from imbalances in tissue $\mathrm{CO}_{2}$ production and pulmonary elimination. If buffer systems are overwhelmed, hypercapnia results in excess free $\mathrm{H}^{+}$in blood, lowering blood $\mathrm{pH}$ which is known as a respiratory acidosis. Conversely, metabolic acidosis results from a build-up of nonvolatile acids (e.g. lactic acid during anaerobic metabolism) or excessive loss of bicarbonate. Regardless of the cause of acidosis, the brain and carotid artery chemoreceptors detect increased $\mathrm{H}^{+}$and stimulate breathing, promoting respiratory $\mathrm{CO}_{2}$ elimination. ${ }^{33}$ In chronic acidosis, renal $\mathrm{HCO}_{3}{ }^{-}$reabsorption and $\mathrm{H}^{+}$ excretion increase to minimize $\mathrm{pH}$ disturbances. ${ }^{33}$

In the maternal-fetal unit

In the fetus, $\mathrm{CO}_{2}$ regulation is limited by immature fetal systems and depends on transfer into the maternal compartment. ${ }^{34-36}$ Carbonic anhydrases $(\mathrm{CA})$, a key catalyst 
in buffering excess $\mathrm{CO}_{2}$, are present in the fetus, yet blood CA levels and functional activity are low compared to adults. ${ }^{37,38}$ However, CA activity has been detected in multiple fetal tissues, which may mitigate the adverse effects of tissue hypercapnia and acidosis. ${ }^{39-44}$ In fetal skin, gastric mucosa, liver, pancreas and kidneys, CA expression is similar to that in adults. ${ }^{40-42}$ Lung CA levels are greatest during fetal life and may play a role in fetal lung liquid secretion. ${ }^{39,42}$ Conversely, fetal brain CA activity increases during gestation, but remains significantly lower than adults, even at term. ${ }^{42-}$ ${ }^{44} \mathrm{CA}$ activity in placental tissues is hypothesized to facilitate $\mathrm{CO}_{2}$ transfer across the placenta into the maternal circulation. ${ }^{45-49}$ However, low placenta CA levels reported in some studies may saturate this mechanism and limit fetal $\mathrm{CO}_{2}$ elimination rates. ${ }^{45-48}$ In animals the capacity for fetal renal bicarbonate excretion and reabsorption increases throughout gestation, suggesting that the fetal kidneys are not a major contributor for acid-base regulation in early- and mid-gestation. ${ }^{36,50}$ Further, as bicarbonate is poorly transported across the placenta and fetal buffer systems are limited and rapidly exhausted, the main mechanism for fetal $\mathrm{CO}_{2}$ elimination is believed to be diffusion across the placenta. ${ }^{34-36,51}$

$\mathrm{CO}_{2}$ diffusion out of the fetal compartment is facilitated by relative maternal hypocapnia induced by physiological adaptations in pregnancy, which increase the partial pressure gradient. ${ }^{52-54}$ Increasing progesterone levels during pregnancy act as a respiratory stimulant, increasing alveolar minute ventilation by $30-50 \%$. Consequently, maternal $\mathrm{PaCO}_{2}$ decreases from $35-40 \mathrm{mmHg}$ to $26-32 \mathrm{mmHg}$ during pregnancy. ${ }^{52-54}$ A compensatory increase in renal bicarbonate excretion minimizes maternal alkalosis, maintaining a maternal $\mathrm{pH}$ of $7.40-7.47$ compared to $7.35-7.45$ in the non-pregnant state..$^{52-54}$ 


\section{Physiological effects of hypercapnia}

While fetal hypercapnia and acidosis during hypoxia have a well-established association with neonatal morbidity and poor neurological outcomes, the consequences of fetal acidosis in the absence of hypoxia are largely unknown. ${ }^{55}$ The effects in preterm neonates and adults are, however, well documented (Table 1) and discussed below.

\section{Cerebrovascular}

Hypercaphic acidosis causes vasodilation of cerebral vessels thereby increasing cerebral blood flow and intracranial pressure. ${ }^{33}$ In adults, hypercapnia decreases cerebral oxygen metabolism, alters cerebral neurotransmission and increases markers of neuronal injury. ${ }^{56-58}$ Studies of permissive hypercapnia in ventilated premature and very low birth weight infants show progressively impaired cerebral blood flow auto-regulation at $\mathrm{PaCO}_{2}$ levels above $45 \mathrm{mmHg}$ and an increasing risk of intraventricular hemorrhage with increasing $\mathrm{PaCO}_{2} .{ }^{59,60}$ Conversely, a more recent large randomized control trial using permissive hypercapnia in extremely low birth weight infants (PHELBI study) did not confirm an increased risk of intraventricular hemorrhage. ${ }^{61}$ Nonetheless, in addition to demonstrating no benefit of permissive hypercapnia, the authors also questioned its safety as necrotizing enterocolitis was more common in hypercapnic infants and was thought to result from impaired intestinal cell function caused by the acidosis. ${ }^{61}$

\section{Cardiovascular}

Hypercaphic acidosis acts locally by directly suppressing myocardial contractility, decreasing heart rate and promoting vasodilation. ${ }^{62}$ However, to maintain cardiac output, hypercapnia also stimulates central sympathetic activity leading to tachycardia, 
increased cardiac contractility and promoting peripheral vasoconstriction. ${ }^{63,64}$ In adults, hypercapnia increases cardiac output, heart rate and risk of arrhythmia, ${ }^{65}$ but peripheral vasodilation limits increases in mean arterial pressure. ${ }^{63}$ With worsening hypercapnia and a pH below 7.2, the central response is impaired resulting in cardiac depression and bradycardia. ${ }^{33,64}$

\section{Immunological}

In vitro and adult clinical studies show that hypercapnia impairs immune cell function and reduces the systemic inflammatory response..$^{66-70}$

\section{Carbon dioxide insufflation for endoscopic surgery}

High solubility, non-combustibility, low cost and wide availability of $\mathrm{CO}_{2}$ make it the gas of choice for abdominal insufflation in laparoscopic surgery. ${ }^{71}$ High gas solubility diminishes the risk of gas embolism which, although a very rare event, has limited treatment options and high mortality..$^{71}$ However, $\mathrm{CO}_{2}$ rapidly absorbs into body tissues causing hypercapnia and acidosis. ${ }^{63,72}$

In infants, there are some concerns with $\mathrm{CO}_{2}$ insufflation for endoscopic procedures, including an age-dependent reduced capacity for $\mathrm{CO}_{2}$ elimination and increased susceptibility to cardiovascular depression and hypotension in response to hypercapnia, compared to older children and adults. ${ }^{73-75}$ Retrospective clinical studies report significant hypercapnia, acidosis and decreased cerebral oxygen saturation during thoracoscopy with $\mathrm{CO}_{2}$ insufflation to repair congenital diaphragmatic hernia and esophageal atresia in neonates. ${ }^{76,77}$ However, long-term neurodevelopmental outcomes are lacking and an overarching scarcity of high quality prospective evidence in this field limits data interpretation. ${ }^{75,78}$ 
Nonetheless, laparoscopic surgery in adults and children is considered safe, especially when abdominal insufflation pressures do not exceed $12 \mathrm{mmHg}$ and pulmonary ventilation is increased to enhance $\mathrm{CO}_{2}$ elimination. ${ }^{79,80}$ In pregnancy, laparoscopy is an increasingly common alternative to open abdominal surgery for intra-abdominal pathology whenever possible..$^{81}$

\section{Animal models of PACI}

Four animal studies investigated the effects of PACI on fetal acid-base status, all using pregnant sheep (Table 2). ${ }^{10-13}$ All four studies observed fetal hypercapnia and acidosis after $\mathrm{CO}_{2}$ insufflation. However, these studies did not include a control group and instead assessed fetal acid-base changes from baseline. This approach does not account for potential effects of fetal surgery and prolonged anesthesia on fetal acid-base status. Additionally, some studies used older anesthetic agents (3\% halothane) that have known fetal acid-base effects. ${ }^{82}$

One study compared the effects of uterine distension using $\mathrm{CO}_{2}$, helium and water and found that only $\mathrm{CO}_{2}$ amniotic insufflation resulted in fetal hypercapnia and acidosis. ${ }^{11}$ Distension with water led to mild fetal hyponatremia and hypochloremia, whereas helium insufflation did not affect fetal acid-base status or electrolytes. These findings suggest fetal acid-base disturbances were associated with the $\mathrm{CO}_{2}$ diffusion and fetal uptake, rather than uterine distention. Additionally, fetoscopic neck dissection and fetal tracheal clipping during $\mathrm{CO}_{2}$ insufflation did not worsen fetal acidemia compared to insufflation-only. ${ }^{13}$

Whilst fetal hypercapnia and acidosis occurred in all four animal studies, the route of $\mathrm{CO}_{2}$ absorption into the fetal bloodstream, whether via fetal skin, placental or fetal vessels or another pathway, was not investigated hence remains unclear. 


\section{Insufflation duration}

In all four studies, fetal acidemia worsened with longer insufflation duration. ${ }^{10-13}$ Gratacos et al had the longest insufflation period (60-minutes) resulting in the largest increase in fetal $\mathrm{PaCO}_{2}$ (from 55 to $88 \mathrm{mmHg}$ ) and decrease in $\mathrm{pH}$ (from 7.24 to 7.06). ${ }^{10-13}$ Importantly, the duration of PACl currently used in published human fetoscopic surgeries averages 183 to 250 minutes, significantly exceeding that tested in animal models. ${ }^{7,9}$

\section{Insufflation pressures}

Altering PACI pressures could have multiple impacts on fetal and maternal wellbeing. Both the insufflation pressure required for adequate uterine distension and the subsequent fetal and maternal effects are potentially influenced by whether the uterus is exteriorized during PACI. Insufflation pressures used for PACI in sheep studies were lower when the uterus was exteriorized during $\mathrm{CO} 2$ insufflation (3-4mmHg vs. 10$15 \mathrm{mmHg}$, Table 1). ${ }^{10-13}$ Uterine exteriorization may reduce pressures required for necessary uterine distension by eliminating additional resistance created by a closed abdominal wall and the intraabdominal contents.

Increasing insufflation pressures increases the partial pressure for $\mathrm{CO}_{2}$, thereby increasing tissue $\mathrm{CO}_{2}$ absorption and thus the severity of resulting hypercapnia and acidosis. Indeed, increasing abdominal $\mathrm{CO}_{2}$ insufflation pressures worsens hypercapnia in adult laparoscopic surgery and increases fetal hypercapnia in pregnant ewes. $83-87$

Another consideration is the mechanical effect of increasing uterine distension. Sheep studies of intrauterine distension with a 'loosely closed' abdomen using saline or medical air showed that intrauterine pressures greater than $20 \mathrm{mmHg}$ and $15 \mathrm{mmHg}$ 
respectively significantly reduced uterine and umbilical artery flow leading to fetal hypoxia. ${ }^{88-90}$ Additionally, where the laparotomy incision is closed, increasing uterine insufflation pressures may increase intra-abdominal pressures and thereby decrease venous return and cardiac output. ${ }^{91-93}$ Increased pressure on the diaphragm also reduces respiratory system compliance, increases airway pressures, reduces inspiratory reserve volumes and decreases functional residual capacity, making the patient more vulnerable to hypoxia and reducing the capacity for pulmonary $\mathrm{CO}_{2}$ elimination. ${ }^{63,80,94}$ However, in spontaneously breathing baboons, it has been shown that intra-abdominal insufflation pressures up to $77 \mathrm{mmHg}$ were rarely lethal, despite significant respiratory distress and hemodynamic compromise. ${ }^{95}$ In the pregnant patient, the gravid uterus exacerbates increased intra-abdominal pressure. ${ }^{52,53}$ Further, pregnancy is associated with a $50 \%$ increased cardiac output, with a $45-50 \%$ increased circulating blood volume and moderate increases in maternal heart rate. ${ }^{53,96-}$ 98 This hyperdynamic cardiovascular state increases vulnerability to cardiopulmonary compromise and reduces compensatory capacity.

$\mathrm{PACl}$ pressures reported in clinical series of fetoscopic MMC repair are in a broad range $(9-30 \mathrm{mmHg})$, with lower maximum pressures reported when the uterus is exteriorized for the procedure $(12 \pm 2 \mathrm{mmHg}) \cdot{ }^{7,9} \mathrm{~A}$ safe pressure range for $\mathrm{PACl}$, has not been identified yet, but is an important consideration because of potential adverse effects for both mother and fetus.

\section{Maternal ventilation during PACI}

During abdominal $\mathrm{CO}_{2}$ insufflation, increasing minute ventilation increases respiratory $\mathrm{CO}_{2}$ elimination, thereby mitigating the associated acidosis in adult humans undergoing laparoscopy ${ }^{80}$ and preventing fetal acid-base disturbances in pregnant 
sheep. ${ }^{87}$ As such, altering maternal ventilation targets during PACl may increase the fetal-maternal $\mathrm{PaCO}_{2}$ gradient and enhance fetal $\mathrm{CO}_{2}$ elimination.

Maternal ventilation targets varied significantly between animal PACI studies..$^{10-13}$ When ventilation settings were fixed at a level producing maternal $\mathrm{PaCO}_{2}$ of $35-$ $40 \mathrm{mmHg}$ prior to insufflation, $\mathrm{PACl}$ resulted in increased maternal $\mathrm{PaCO}_{2}$ and, to a greater extent, fetal $\mathrm{PaCO}_{2}{ }^{12,13}$ Furthermore, fetal $\mathrm{PaCO}_{2}$ increases during $\mathrm{PACl}$ even when maternal $\mathrm{PaCO}_{2}$ is maintained with ventilation adjustments. ${ }^{10}$ It is suggested that further lowering maternal $\mathrm{PaCO}_{2}$ levels (hypocapnia) with maternal hyperventilation could theoretically enhance fetal $\mathrm{CO}_{2}$ elimination. On the other hand, hyperventilation and hypocapnia $\left(\mathrm{PaCO}_{2} 20 \mathrm{mmHg}\right)$ in pregnant ewes is associated with reduced uteroplacental blood flow and decreased fetal oxygenation. ${ }^{99}$ Interestingly, uterine artery flow remains diminished during maternal hyperventilation when $\mathrm{CO}_{2}$ is added to inspired air to establish maternal normocapnia and hypercapnia. ${ }^{99}$ Thus the increase in mean airway pressure during hyperventilation may impair uterine artery flow by reducing venous return. Additionally, fetal oxygenation is only impaired during maternal hypocapnic periods, which could be explained by a left shift in the maternal oxygen-hemoglobin dissociation curve. ${ }^{99}$ This would increase maternal hemoglobin oxygen affinity and impair oxygen offloading to the fetus. ${ }^{100,101}$

The effect of maternal hyperventilation and hypocapnia during PACl was addressed in two animal studies with conflicting outcomes. Saiki et al found fetal hypercapnia and acidosis was completely reversed by maternal hyperventilation, whilst Gratacos et al found fetal acid-base changes could be reduced but not prevented. ${ }^{12,13}$ Saiki et al reported significant decreases in fetal $\mathrm{PaO}_{2}$ during maternal hyperventilation, whilst Gratacos et al reported no change. ${ }^{12,13}$ Multiple differences between the studies may have contributed to conflicting outcomes. Saiki et al had a shorter insufflation period 
(30 vs. 60 -minutes) and slightly lower maternal $\mathrm{PaCO}_{2}$ targets (25 - 28 vs. $28-$ $30 \mathrm{mmHg}$ ) compared to Gratacos et al. ${ }^{12,13}$ Saiki et al reported increased maternal hemodynamics (systolic blood pressure 124 - 142 vs. $98 \mathrm{mmHg}$, heart rate 128 - 157 vs. 79bpm), which may have increased placental blood flow and facilitated fetal elimination of $\mathrm{CO}_{2}{ }^{12,13}$

\section{Neurological effects of PACI}

The effects of $\mathrm{PACl}$ on the developing fetal brain at insufflation pressures and durations used clinically remain unclear. Kohl et al exposed fetal lambs to PACI and followed them to term, observing no obvious abnormalities in neonatal movements or feeding patterns and no gross histological evidence of neonatal brain hemorrhage, infarction, inflammation, or abnormal cortical maturation on $\mathrm{H} \& \mathrm{E}$ staining. ${ }^{1}$ However, compared to clinical fetoscopic surgery, this study used shorter PACI durations (45 80 vs. 140 - 450-minutes) and lower maximum insufflation pressures (7 - 15 vs. 9 $30 \mathrm{mmHg}){ }^{1,7-9}$ Additionally, subtle neurological impairment that is clinically significant in human newborns may not be evident on gross observation of newborn lambs. Likewise, subtle markers of neonatal brain injury may require more rigorous histological analysis to identify. Although reassuring at low pressure for a short duration, this single study is not sufficient to demonstrate fetal neurological safety of pressures and duration used clinically.

\section{Uterine membrane effects of PACI}

Whilst abdominal $\mathrm{CO}_{2}$ insufflation for laparoscopy is known to cause peritoneal tissue damage, ${ }^{102-104}$ little is known about the effects of $\mathrm{PACl}$ on uterine membranes. 
Replacing amniotic fluid with a cold, dry gas introduces potential risks of uterine and fetal membrane dehydration and inflammation, such as described in peritoneal membranes during insufflation with cold dry $\mathrm{CO}_{2} \cdot{ }^{102-104}$ Theoretically, these effects could contribute to an apparently higher incidence of premature labor following fetoscopic MMC repair, and may, in this way, indirectly have consequences for fetal wellbeing. ${ }^{5-8}$ Importantly, using heated-humidified $\mathrm{CO}_{2}$ for $\mathrm{PACl}$ may mitigate such effects, as has been observed for abdominal $\mathrm{CO}_{2}$ insufflation. Indeed, using heatedhumidified $\mathrm{CO}_{2}$ reduces peritoneal damage, adhesion formation, intraoperative hypothermia and postoperative pain observed using unheated gas. ${ }^{103-105}$ The potential benefits of using heated-humidified $\mathrm{CO}_{2}$ clinically are also suggested by promising preliminary results observed in a recent case series. ${ }^{5}$ However, other procedural factors such as lower insufflation pressures, uterus exteriorization and primary skin closure of MMC defect are also unique to this series.

\section{Other candidate gases for insufflation}

Using alternative gases for uterine distension has been suggested to avoid fetal hypercapnia and acidosis associated with $\mathrm{CO}_{2}$ absorption. Medical air and oxygen are highly combustible, whilst low solubility of nitrogen increases risk of gas embolism. ${ }^{71}$ Nitrous oxide and helium are considered safe alternatives because of their noncombustible properties. Indeed, sheep studies do not demonstrate fetal hypercapnic acidosis during uterine distension with helium or abdominal insufflation with either helium or nitrous oxide. ${ }^{11,86,87}$ However, uterine insufflation may have mechanical effects on fetal-placental blood flow, as described previously, that would presumably occur independent of the distension media used. .5-90 $^{-90}$ 


\section{Limitations of the ovine model}

Pregnant sheep are commonly used for pregnancy related research, largely due to the possibility for invasive placental and fetal physiological monitoring. ${ }^{106}$ Its relatively large size and uterine quiescence permits fetal and placental manipulation and instrumentation without high risk of preterm labor. ${ }^{106-108}$ Pregnant ewes have a relatively long gestation and deliver a precocious offspring, allowing assessment of the effects of PACI at clinically relevant times in gestation. The fetal sheep brain is well-studied and considered a reliable model of gross human fetal brain injury owing to sufficient anatomical and developmental similarities. ${ }^{109-111}$

However, the ovine model has limitations when translating the effects of PACl to human pregnancies. The sheep uterus is thought to be more compliant than the human uterus, thereby increasing its susceptibility to overdistension and potentially overestimating the observed effects of PACI. ${ }^{112}$ The relative quiescence of the sheep uterus precludes its use for assessing preterm birth risk in response to PACI. ${ }^{106-108}$ Additionally, The sheep placenta consists of multiple fetal cotyledons paired with maternal caruncles interspersed throughout the uterine wall (Figure $2(b, c)$ ). Fetal cotyledons are joined by inter-cotelydonary fetal vessels that travel between the fetal membranes (Figure $2(\mathrm{~b}, \mathrm{c})$ ). In contrast, cotyledons comprising the human placenta join adjacently to form a single discoid structure (Figure 2 (a)). Thus, it is possible that inter-cotyledonary fetal vessels in sheep provide a greater surface area for $\mathrm{CO}_{2}$ absorption or that 'stretching' of these vessels by uterine distension may impair placental gaseous exchange. Furthermore, the placental unit in sheep is synepitheliochorial, with additional maternal tissue layers separating the maternal and fetal vasculature compared to the human hemochorial placenta. ${ }^{112,113}$ Nonetheless, 
numerous studies demonstrate the feasibility of using the ovine model to investigate human placental physiology, including gaseous diffusion. ${ }^{107}$

Finally, potential subtle yet clinically significant human fetal brain injury and neurological impairment may not be well assessed using an ovine model. Whilst primates are an alternative animal model more closely reflecting the human uterine membrane and placental structure, ${ }^{106,114}$ this species is financial and ethically a limited resource in animal research. ${ }^{106,114,115}$

\section{Conclusion}

In the last decades, fetoscopic myelomeningocoele repair has been suggested as an alternative to open fetal surgery. ${ }^{5-9}$ The complexity of this operation still requires amniodistention using a gas, and $\mathrm{CO}_{2}$ is clinically the gas of choice so far. However, there is concern about its use. ${ }^{116}$ In sheep, PACI causes fetal hypercapnia and acidosis and the fetal consequences of this acid-base disturbance are not well understood. ${ }^{10-13}$ Clinical outcomes following the use of PACI are difficult to interpret, especially because there is a large variability between current clinical techniques, including regarding insufflation pressures, duration, gas temperature and humidity. On the other hand, the available literature report no major adverse effects that can be clearly related to iatrogenic fetal acidosis during fetoscopy. Nevertheless, we believe that there are still very relevant research questions concerning the use of $\mathrm{PACl}$ in humans to guide future studies, such as examining the effects on fetal brain oxygen delivery and metabolism, fetal brain injury, placental blood flow and the uterine membranes. 


\section{References:}

1. Kohl T, Ziemann M, Weinbach J, et al. Partial amniotic carbon dioxide insufflation during minimally invasive fetoscopic interventions seems safe for the fetal brain in sheep. $J$ Laparoendosc Adv Surg Tech A 2010;20:651-3.

2. Kohl T, Gembruch U. Current status and prospects of fetoscopic surgery for spina bifida in human fetuses. Response to Fichter et al: Fetal spina bifida repair--current trends and prospects of intrauterine neurosurgery (Fetal Diagn Ther 2008;23:271-286). Fetal Diagn Ther 2008;24:318-20.

3. Bruner JP, Richards WO, Tulipan NB, et al. Endoscopic coverage of fetal myelomeningocele in utero. Am J Obstet Gynecol 1999;180:153-8.

4. Bruner JP, Tulipan NB, Richards WO, et al. In utero repair of myelomeningocele: A comparison of endoscopy and hysterotomy. Fetal Diagn Ther 2000;15:83-8.

5. Degenhardt J, Schurg R, Winarno A, et al. Percutaneous minimal-access fetoscopic surgery for spina bifida aperta. Part II: maternal management and outcome. Ultrasound Obstet Gynecol 2014;44:525-31.

6. Graf K, Kohl T, Neubauer BA, et al. Percutaneous minimally invasive fetoscopic surgery for spina bifida aperta. Part III: neurosurgical intervention in the first postnatal year. Ultrasound Obstet Gynecol 2016;47:158-61.

7. Kohl T. Percutaneous minimally invasive fetoscopic surgery for spina bifida aperta. Part I: surgical technique and perioperative outcome. Ultrasound Obstet Gynecol 2014;44:515-24.

8. Pedreira DAL, Zanon N, Nishikuni K, et al. Endoscopic surgery for the antenatal treatment of myelomeningocele: The CECAM trial. Am J Obstet Gynecol 2016;214:111.e1.$e 11$.

9. Belfort MA, Whitehead WE, Shamshirsaz AA, et al. Fetoscopic open neural tube defect repair: Development and refinement of a two-port, carbon dioxide insufflation technique. Obstet Gynecol 2017;129:734-43.

10. Luks Fl, Deprest J, Marcus M, et al. Carbon dioxide pneumoamnios causes acidosis in fetal lamb. Fetal Diagn Ther 1994;9:105-9.

11. Pelletier GJ, Srinathan SK, Langer JC. Effects of intraamniotic helium, carbon dioxide, and water on fetal lambs. J Pediatr Surg 1995;30:1155-8.

12. Saiki Y, Litwin DE, Bigras JL, et al. Reducing the deleterious effects of intrauterine CO2 during fetoscopic surgery. J Surg Res 1997;69:51-4.

13. Gratacos E, Wu J, Devlieger R, et al. Effects of amniodistention with carbon dioxide on fetal acid-base status during fetoscopic surgery in a sheep model. Surg Endosc 2001;15:368-72.

14. Adzick NS, Thom EA, Spong CY, et al. A randomized trial of prenatal versus postnatal repair of myelomeningocele. New Engl J Med 2011;364:993-1004.

15. Samdani AF, Akalan N, Macyszyn L, et al. Intraspinal pathology. The Growing Spine: Management of Spinal Disorders in Young Children, Second Edition: Springer Berlin Heidelberg; 2015:249-63.

16. Padmanabhan R. Etiology, pathogenesis and prevention of neural tube defects. Congenit Anom (Kyoto) 2006;46:55-67. 
17. Tortori-Donati P, Rossi A, Cama A. Spinal dysraphism: A review of neuroradiological features with embryological correlations and proposal for a new classification.

Neuroradiology 2000;42:471-91.

18. Stiefel D, Copp AJ, Meuli M. Fetal spina bifida in a mouse model: Loss of neural function in utero. J Neurosurg 2007;106:213-21.

19. Paek BW, Farmer DL, Wilkinson CC, et al. Hindbrain herniation develops in surgically created myelomeningocele but is absent after repair in fetal lambs. Am J Obstet Gynecol 2000;183:1119-23.

20. Wilson RD, Johnson MP, Flake AW, et al. Reproductive outcomes after pregnancy complicated by maternal-fetal surgery. Am J Obstet Gynecol 2004;191:1430-6.

21. Wilson RD, Lemerand K, Johnson MP, et al. Reproductive outcomes in subsequent pregnancies after a pregnancy complicated by open maternal-fetal surgery (19962007). Am J Obstet Gynecol 2010;203:209.e1-.e6.

22. Belfort MA, Whitehead WE, Shamshirsaz AA, et al. Fetoscopic Repair of Meningomyelocele. Obstet Gynecol 2015;126:881-4.

23. Baschat A, Ahn E, Murphy J, et al. Fetal blood gas values during fetoscopic myelomeningocele repair performed under carbon dioxide insufflation. Ultrasound Obstet Gynecol 2018.

24. Carroll JJ, Slupsky JD, Mather AE. The Solubility of Carbon Dioxide in Water at Low Pressure. Journal of Physical and Chemical Reference Data 1991;20:1201-9.

25. Joyeux L, Engels AC, Russo FM, et al. Fetoscopic versus Open Repair for Spina Bifida Aperta: A Systematic Review of Outcomes. Fetal Diagn Ther 2016;39:161-71.

26. Petersen SG, Gibbons KS, Luks FI, et al. The Impact of Entry Technique and Access Diameter on Prelabour Rupture of Membranes Following Primary Fetoscopic Laser Treatment for Twin-Twin Transfusion Syndrome. Fetal Diagn Ther 2016.

27. Kabagambe SK, Jensen GW, Chen YJ, et al. Fetal Surgery for Myelomeningocele: A Systematic Review and Meta-Analysis of Outcomes in Fetoscopic versus Open Repair. Fetal Diagn Ther 2017.

28. Blumenfeld YJ, Belfort MA. Updates in fetal spina bifida repair. Current Opinion in Obstetrics and Gynecology 2018;30:123-9.

29. Joyeux L, De Bie F, Danzer E, et al. Safety and efficacy of fetal surgery techniques to close a spina bifida defect in the fetal lamb model: A systematic review. Prenatal Diagnosis 2018;38:231-42.

30. Kohl T, Tchatcheva K, Weinbach J, et al. Partial amniotic carbon dioxide insufflation $(\mathrm{PACl})$ during minimally invasive fetoscopic surgery: early clinical experience in humans. Surg Endosc 2010;24:432-44.

31. Supuran CT. Carbonic anhydrases - A overview. Current Pharmaceutical Design 2008;14:603-14.

32. Supuran CT, De Simone G. Carbonic Anhydrases: An Overview. Carbonic Anhydrases as Biocatalysts: From Theory to Medical and Industrial Applications2015:3-13.

33. Palmer J. Acid-base homeostasis and derangements. Equine Fluid Therapy: Wiley Blackwell; 2015:101-25.

34. Blechner JN. Maternal-fetal acid-base physiology. Clin Obstet Gynecol 1993;36:3-12.

35. Creasy RK, Resnik R, lams JD, et al. Creasy and Resnik's Maternal-Fetal Medicine: Principles and Practice. 7th ed: Elsevier Health Sciences; 2013. 
36. Seri I. Acid-Base Homeostasis in the Fetus and Newborn. Nephrology and Fluid/Electrolyte Physiology: Elsevier Inc.; 2012:105-13.

37. Holland RAB, Comis A. Carbonic anhydrase activity in the blood of adult sheep, fetal sheep and lambs. Comparative Biochemistry and Physiology -- Part A: Physiology 1987;86:673-7.

38. Akbar SA, Brown PR. Measurement of human erythrocyte CAI and CAll in adult, newborn, and fetal blood. Clinical Biochemistry 1996;29:157-64.

39. Lönnerholm G, Wistrand P. Carbonic anhydrase in the human fetal lung. Pediatr Res 1982;16:407-11.

40. Lönnerholm G, Wistrand PJ. Carbonic anhydrase in the human fetal kidney. Pediatr Res 1983;17:390-7.

41. Liao SY, Lerman MI, Stanbridge EJ. Expression of transmembrane carbonic anhydrases, CAIX and CAXII, in human development. BMC Developmental Biology 2009;9.

42. Carter ND, Fryer A, Grant AG, et al. Membrane specific carbonic anhydrase (CAIV) expression in human tissues. BBA - Biomembranes 1990;1026:113-6.

43. Catala M. Carbonic anhydrase activity during development of the choroid plexus in the human fetus. Child's Nerv Syst 1997;13:364-8.

44. Kida E, Palminiello S, Golabek AA, et al. Carbonic anhydrase II in the developing and adult human brain. Journal of Neuropathology and Experimental Neurology 2006;65:664-74.

45. Aliakbar S, Brown PR, Jauniaux E, et al. Measurement of carbonic anhydrase isoenzymes in early human placental tissues. Biochemical Society Transactions 1990;18:670.

46. Ridderstråle $Y$, Persson E, Dantzer V, et al. Carbonic anhydrase activity in different placenta types: A comparative study of pig, horse, cow, mink, rat, and human. Microscopy Research and Technique 1997;38:115-24.

47. Aliakbar S, Brown PR, Nicolaides KH. Localization of CAI and CAll isoenzymes in normal term human placenta by immunofluorescence techniques. Placenta 1990;11:35-9.

48. Kaufmann P, Mühlhauser J, Crescimanno C, et al. Immunohistochemistry of carbonic anhydrase in human placenta and fetal membranes. Histochemistry 1994;101:91-8.

49. Gutknecht J, Bisson MA, Tosteson FC. Diffusion of carbon dioxide through lipid bilayer membranes. Journal of General Physiology 1977;69:779-94.

50. Kesby GJ, Lumbers ER. The effects of metabolic acidosis on renal function of fetal sheep. The Journal of Physiology 1988;396:65-74.

51. Hatano H, Leichtwerß HP, Schröder $\mathrm{H}$. Uptake of bicarbonate/CO2 in the isolated guinea pig placenta. Placenta 1989;10:213-21.

52. Bobrowski RA. Pulmonary physiology in pregnancy. Clin Obstet Gynecol 2010;53:285-300.

53. Phillips J, Covington M, Osol G. Maternal Physiological Adaptations to Pregnancy. Anesthesia and the Fetus: Wiley-Blackwell; 2012:19-24.

54. Lucius $\mathrm{H}$, Gahlenbeck $\mathrm{H}$, Kleine $\mathrm{HO}$, et al. Respiratory functions, buffer system, and electrolyte concentrations of blood during human pregnancy. Respir Physiol 1970;9:311-7.

55. Malin GL, Morris RK, Khan KS. Strength of association between umbilical cord pH and perinatal and long term outcomes: systematic review and meta-analysis. BMJ 2010;340.

56. Kliefoth AB, Grubb Jr RL, Raichle ME. Depression of cerebral oxygen utilization by hypercapnia in the rhesus monkey. J NEUROCHEM 1979;32:661-3. 
57. Wang YZ, Xu TL. Acidosis, acid-sensing ion channels, and neuronal cell death. Mol Neurobiol 2011;44:350-8.

58. Liu LL, Bao N, Lu HW. Effects of CO2 Pneumoperitoneum on the Cognitive Function of Patients Undergoing Gynecologic Laparoscopy. Gynecol Obstet Invest 2016;81:90-5.

59. Kaiser JR, Gauss CH, Williams DK. The effects of hypercapnia on cerebral autoregulation in ventilated very low birth weight infants. Pediatr Res 2005;58:931-5.

60. Kaiser JR, Gauss CH, Pont MM, et al. Hypercapnia during the first 3 days of life is associated with severe intraventricular hemorrhage in very low birth weight infants. $J$ Perinatol 2006;26:279-85.

61. Thome UH, Genzel-Boroviczeny O, Bohnhorst B, et al. Permissive hypercapnia in extremely low birthweight infants (PHELBI): A randomised controlled multicentre trial. The Lancet Respiratory Medicine 2015;3:534-43.

62. Cingolani HE, Mattiazzi AR, Blesa ES, et al. Contractility in Isolated Mammalian Heart Muscle after Acid-Base Changes. Circulation Research 1970;26:269-78.

63. Raman JD, Cadeddu JA. Pneumoperitoneum: Physiologic Effects. Smith's Textbook of Endourology: 3rd Edition: Wiley-Blackwell; 2012:811-26.

64. Price HL. Effects of carbon dioxide on the cardiovascular system.

ANESTHESIOLOGY 1960;21:652-63.

65. Scott DB, Julian DG. Observations on cardiac arrythmias during laparoscopy. Br Med J 1972;1:411-3.

66. West MA, Baker J, Bellingham J. Kinetics of decreased LPS-stimulated cytokine release by macrophages exposed to CO2 1. J Surg Res 1996;63:269-74.

67. West MA, Hackam DJ, Baker J, et al. Mechanism of decreased in vitro murine macrophage cytokine release after exposure to carbon dioxide: Relevance to laparoscopic surgery. Ann Surg 1997;226:179-90.

68. Chekan EG, Nataraj C, Clary EM, et al. Intraperitoneal immunity and pneumoperitoneum. Surg Endosc 1999;13:1135-8.

69. Coakley RJ, Taggart C, Greene C, et al. Ambient pCO2 modulates intracellular pH, intracellular oxidant generation, and interleukin-8 secretion in human neutrophils. J Leukocyte Biol 2002;71:603-10.

70. Sietses C, Blomberg MEv, Eijsbouts QAJ, et al. The influence of CO2 versus helium insufflation or the abdominal wall lifting technique on the systemic immune response. Surg Endosc 2002;16:525-8.

71. Uhlich GA. Laparoscopy: the question of the proper gas. Gastrointest Endosc 1982;28:212-3.

72. Alexander GD, Noe FE, Brown EM. Anesthesia for pelvic laparoscopy. Anesth Analg 1969;48:14-8.

73. McHoney M, Corizia L, Eaton S, et al. Carbon dioxide elimination during laparoscopy in children is age dependent. J Pediatr Surg 2003;38:105-10.

74. Metzelder ML, Kuebler JF, Huber D, et al. Cardiovascular responses to prolonged carbon dioxide pneumoperitoneum in neonatal versus adolescent pigs. Surg Endosc Interv Tech 2010;24:670-4.

75. Lacher M, Kuebler JF, Dingemann J, et al. Minimal invasive surgery in the newborn: Current status and evidence. Seminars in Pediatric Surgery 2014;23:249-56. 
76. Bishay M, Giacomello L, Retrosi G, et al. Decreased cerebral oxygen saturation during thoracoscopic repair of congenital diaphragmatic hernia and esophageal atresia in infants. J Pediatr Surg 2011;46:47-51.

77. Zani A, Lamas-Pinheiro R, Paraboschi I, et al. Intraoperative acidosis and hypercapnia during thoracoscopic repair of congenital diaphragmatic hernia and esophageal atresia/tracheoesophageal fistula. Paediatric Anaesthesia 2017;27:841-8.

78. Dingemann C, Ure B, Dingemann J. Thoracoscopic procedures in pediatric surgery: What is the evidence? Eur J Pediatr Surg 2014;24:14-9.

79. Neudecker J, Sauerland S, Neugebauer E, et al. The European Association for Endoscopic Surgery clinical practice guideline on the pneumoperitoneum for laparoscopic surgery. Surg Endosc 2002;16:1121-43.

80. Motew M, Ivankovich AD, Bieniarz J, et al. Cardiovascular effects and acid-base and blood gas changes during laparoscopy. Am J Obstet Gynecol 1973;115:1002-12.

81. Corneille MG, Gallup TM, Bening T, et al. The use of laparoscopic surgery in pregnancy: evaluation of safety and efficacy. Am J Surg 2010;200:363-7.

82. Sabik JF, Assad RS, Hanley FL. Halothane as an anesthetic for fetal surgery. J Pediatr Surg 1993;28:542-7.

83. Lister DR, Rudston-Brown B, Warriner CB, et al. Carbon dioxide absorption is not linearly related to intraperitoneal carbon dioxide insufflation pressure in pigs.

ANESTHESIOLOGY 1994;80:129-36.

84. Khan F, Manzoor A, Jamal S. Low pressure pneumoperitonium laparoscopic cholecystectomy: A comparison of intra-operative hemodynamic stability and physiological changes with standard pressure pneumoperitonium laparoscopic cholecystectomy. Rawal Med J 2015;40:299-303.

85. Curet MJ, Vogt DA, Schob O, et al. Effects of $\mathrm{CO} 2$ pneumoperitoneum in pregnant ewes. J Surg Res 1996;63:339-44.

86. Curet MJ, Weber DM, Sae A, et al. Effects of helium pneumoperitoneum in pregnant ewes. Surg Endosc 2001;15:710-4.

87. Hunter JG, Swanstrom L, Thornburg K. Carbon dioxide pneumoperitoneum induces fetal acidosis in a pregnant ewe model. Surg Endosc 1995;9:272-9.

88. Skarsgard ED, Bealer JF, Meuli M, et al. Fetal endoscopic ('Fetendo') surgery: The relationship between insufflating pressure and the fetoplacental circulation. J Pediatr Surg 1995;30:1165-8.

89. Fauza DO, Fishman SJ. Fetal carotid blood flow during videofetoscopy. J Pediatr Surg 1998;33:1737-40.

90. Fauza DO, Rawn J, Fishman SJ. Fetal response to neutral gas and liquid media for intraamniotic distension. J Pediatr Surg 1999;34:591-4.

91. Ivankovich AD, Miletich DJ, Albrecht RF, et al. Cardiovascular effects of intraperitoneal insufflation with carbon dioxide and nitrous oxide in the dog.

ANESTHESIOLOGY 1975;42:281-7.

92. Richardson JD, Trinkle JK. Hemodynamic and respiratory alterations with increased intra-abdominal pressure. J Surg Res 1976;20:401-4.

93. Kashtan J, Green JF, Parsons EQ, et al. Hemodynamic effects of increased abdominal pressure. J Surg Res 1981;30:249-55.

94. Bardoczky GI, Engelman E, Levarlet M, et al. Ventilatory effects of pneumoperitoneum monitored with continuous spirometry. ANAESTHESIA 1993;48:309-11. 
95. D'Hooghe TM, Bambra CS, Farah IO, et al. High intraabdominal pressure: Effects on clinical parameters and lung pathology in baboons (Papio cynocephalus and Papio anubis). Am J Obstet Gynecol 1993;169:1352-6.

96. Tedesco MM, Curet MJ. Laparoscopy in the pregnant patient. Nezhat's Operative Gynecologic Laparoscopy and Hysteroscopy: Cambridge University Press; 2008:499-508.

97. O'Rourke N, Kodali BS. Laparoscopic surgery during pregnancy. Curr Opin Anaesthesiol 2006;19:254-9.

98. Clark SL, Cotton DB, Lee W, et al. Central hemodynamic assessment of normal term pregnancy. Am J Obstet Gynecol 1989;161:1439-42.

99. Levinson G, Shnider SM, DeLorimier AA, et al. Effects of maternal hyperventilation on uterine blood flow and fetal oxygenation and acid base status. ANESTHESIOLOGY 1974;40:340-7.

100. Bohr C, Hasselbalch K, Krogh A. Concerning a Biologically Important Relationship The Influence of the Carbon Dioxide Content of Blood on its Oxygen Binding. Skand Arch Physiol 1904;16:401-12.

101. Collins JA, Rudenski A, Gibson J, et al. Relating oxygen partial pressure, saturation and content: The haemoglobin-oxygen dissociation curve. Breathe 2015;11:194-201.

102. Carpinteri S, Sampurno S, Bernardi MP, et al. Peritoneal Tumorigenesis and Inflammation are Ameliorated by Humidified-Warm Carbon Dioxide Insufflation in the Mouse. Ann Surg Oncol 2015;22:1540-7.

103. Binda MM. Humidification during laparoscopic surgery: overview of the clinical benefits of using humidified gas during laparoscopic surgery. Arch Gynecol Obstet 2015;292:955-71.

104. Peng $\mathrm{Y}$, Zheng M, Ye Q, et al. Heated and Humidified CO2 Prevents Hypothermia, Peritoneal Injury, and Intra-Abdominal Adhesions During Prolonged Laparoscopic Insufflations. J Surg Res 2009;151:40-7.

105. Balayssac D, Pereira B, Bazin JE, et al. Warmed and humidified carbon dioxide for abdominal laparoscopic surgery: meta-analysis of the current literature. Surg Endosc Interv Tech 2016:1-12.

106. Deprest J, Jani J, Lewi L, et al. Fetoscopic surgery: encouraged by clinical experience and boosted by instrument innovation. Semin Fetal Neonatal Med 2006;11:398412.

107. Barry JS, Anthony RV. The pregnant sheep as a model for human pregnancy. Theriogenology 2008;69:55-67.

108. Dreyfus M, Becmeur F, Schwaab C, et al. The pregnant ewe: An animal model for fetoscopic surgery. European Journal of Obstetrics Gynecology and Reproductive Biology 1997;71:91-4.

109. Back SA, Riddle A, Hohimer AR. Role of instrumented fetal sheep preparations in defining the pathogenesis of human periventricular white-matter injury. J Child Neurol 2006;21:582-9.

110. van den Heuij LG, Wassink G, Gunn AJ, et al. Using pregnant sheep to model developmental brain damage. Neuromethods: Humana Press Inc.; 2016:327-41.

111. Back SA, Riddle A, Roger Hohimer A. The sheep as a model of brain injury in the premature infant. Animal Models of Neurodevelopmental Disorders: Springer New York; 2015:107-28.

112. Osol G, Mandala M. Maternal uterine vascular remodeling during pregnancy. Physiology (Bethesda) 2009;24:58-71.

This article is protected by copyright. All rights reserved. 
113. Sammin D, Markey B, Bassett $H$, et al. The ovine placenta and placentitis-A review. Veterinary Microbiology 2009;135:90-7.

114. Harrison MR, Anderson J, Rosen MA, et al. Fetal surgery in the primate I. Anesthetic, surgical, and tocolytic management to maximize fetal-Neontal survival. J Pediatr Surg 1982;17:115-22.

115. George TM, Fuh E. Review of Animal Models of Surgically Induced Spinal Neural Tube Defects: Implications for Fetal Surgery. Pediatric Neurosurgery 2003;39:81-90.

116. Moise KJ, Flake A. Fetoscopic Open Neural Tube Defect Repair: Development and Refinement of a Two-Port, Carbon Dioxide Insufflation Technique. Obstet Gynecol 2017;130:648.

117. Van Duinen MA, Schruers KRJ, Maes M, et al. CO2 challenge induced HPA axis activation in panic. Int J Neuropsychopharmacol 2007;10:797-804. 
Table 1. Summary of System Responses to Hypercapnia

\begin{tabular}{|c|c|}
\hline System & Effects of Hypercapnia \\
\hline Cerebral & $\begin{array}{l}\uparrow \text { Cerebral Blood Flow }{ }^{33} \\
\uparrow \text { Intracranial Pressure } \\
\downarrow \text { Cerebral metabolic rate of oxygen consumption } \\
56 \\
\downarrow \text { NMDA and GABA brain receptor activity }{ }^{57} \\
\text { Neuronal injury }{ }^{58}\end{array}$ \\
\hline Cardiovascular & $\begin{array}{l}\uparrow \text { Cardiac Output ( } \downarrow \text { if severe }-\mathrm{pH}<7.2 \text { ) } \\
\uparrow \text { Heart Rate }(\downarrow \text { if severe }-\mathrm{pH}<7.2) \\
\uparrow \text { Myocardial oxygen demand } \\
\downarrow \text { Systemic Vascular Resistance } \\
\text { Small } \uparrow \text { Mean Arterial Pressure }{ }^{33,64} \\
\text { Cardiac arrhythmias }{ }^{65}\end{array}$ \\
\hline Respiratory & $\uparrow$ Minute ventilation ${ }^{33}$ \\
\hline Endocrine & $\uparrow$ Cortisol ${ }^{117}$ \\
\hline Immunological & $\begin{array}{l}\downarrow \text { Immune cell function }{ }^{66-70} \\
\downarrow \text { Systemic inflammatory response }{ }^{66-70}\end{array}$ \\
\hline
\end{tabular}


Table 2. Studies Monitoring Fetal Acid Base Status During PACI

\begin{tabular}{|c|c|c|c|c|}
\hline & Luks, $1994^{10}$ & Pelletier, $1995^{11}$ & Saiki, $1997^{12}$ & Gratacos, $2001^{13}$ \\
\hline $\begin{array}{l}\text { Gestationt } \\
\text { (days) }\end{array}$ & $95-105$ & 120 & 105 & $92-100$ \\
\hline $\begin{array}{l}\text { Uterus } \\
\text { exteriorized }\end{array}$ & Yes & $\begin{array}{l}\text { No, laparotomy } \\
\text { incision open }\end{array}$ & $\begin{array}{l}\text { No, laparotomy } \\
\text { incision closed }\end{array}$ & Yes \\
\hline $\begin{array}{l}\text { Insufflation } \\
\text { Pressure } \\
(\mathrm{mmHg})\end{array}$ & $3-4$ & 15 & 10 & $4-5$ \\
\hline $\begin{array}{l}\text { Insufflation } \\
\text { Duration } \\
\text { (minutes) }\end{array}$ & 30 & 30 & 30 & 60 \\
\hline $\begin{array}{l}\text { Materna } \\
\text { Ventilati } \\
\text { goals }\end{array}$ & $\begin{array}{l}\text { Maintain end } \\
\text { tidal } \mathrm{CO}_{2} \text { of } \\
30 \mathrm{mmHg} \\
\left(\sim \mathrm{PaCO}_{2}\right. \\
38 \mathrm{mmHg}) \\
\text { throughout } \\
\text { insufflation }\end{array}$ & NS & $\begin{array}{l}\text { Obtain } \mathrm{PaCO}_{2} 35- \\
40 \text { prior to } \\
\text { insufflation. } \\
\text { Settings fixed and } \\
\mathrm{PaCO}_{2} \text { allowed to } \\
\text { rise during } \\
\text { insufflation. }\end{array}$ & $\begin{array}{l}\text { Obtain } \mathrm{PaCO}_{2} 38- \\
40 \text { prior to } \\
\text { insufflation. } \\
\text { Settings fixed and } \\
\mathrm{PaCO}_{2} \text { allowed to } \\
\text { rise during } \\
\text { insufflation }\end{array}$ \\
\hline \multicolumn{5}{|c|}{ Fetal Acid Base $\ddagger$} \\
\hline $\mathrm{PaCO}$ & $\begin{array}{c}57.6 \pm 1.6 \rightarrow \\
\quad 87 \pm 7^{c}\end{array}$ & $64 \pm 4 \rightarrow 83 \pm 6^{c}$ & $51 \pm 3 \rightarrow 72 \pm 5^{c}$ & $55 \pm 3 \rightarrow 88 \pm 3^{c}$ \\
\hline pH & $\begin{array}{c}7.22 \pm 0.03 \rightarrow \\
7.11 \pm 0.08^{c}\end{array}$ & $\begin{array}{c}7.26 \pm 0.03 \rightarrow \\
7.16 \pm 0.04 \S\end{array}$ & $\begin{array}{c}7.35 \pm 0.01 \rightarrow \\
7.24 \pm 0.03^{c}\end{array}$ & $\begin{array}{c}7.24 \pm 0.01 \rightarrow \\
7.06 \pm 0.03^{c}\end{array}$ \\
\hline $\mathrm{PaO}_{2}$ & "Stable" & $20 \pm 2 \rightarrow 24 \pm 1 \S$ & $24 \pm 2 \rightarrow 28 \pm 3$ & $19 \pm 1 \rightarrow 22 \pm 2$ \\
\hline \multicolumn{5}{|c|}{ Maternal Acid Base $\ddagger$} \\
\hline $\mathrm{PaCO}_{2}$ & $\begin{array}{l}\text { 38ף throughout } \\
\text { insufflation }\end{array}$ & $40 \pm 4 \rightarrow 47 \pm 5$ & $\sim 38 \rightarrow \sim 47$ & $40 \pm 1 \rightarrow 49 \pm 1^{c}$ \\
\hline $\mathrm{pH}$ & & $\begin{array}{c}7.32 \pm 0.03 \rightarrow \\
7.29 \pm 0.03\end{array}$ & $\begin{array}{c}7.33-7.38 \rightarrow 7.28- \\
7.32\end{array}$ & $\begin{array}{c}7.38 \pm 0.02 \rightarrow \\
7.33 \pm 0.02^{c}\end{array}$ \\
\hline
\end{tabular}




\begin{tabular}{|l|l|c|c|c|}
\hline $\mathrm{PaO}_{2}$ & & $161 \pm 32 \rightarrow$ & $333 \pm 53 \rightarrow$ & $222 \pm 22 \rightarrow 226 \pm 24$ \\
& & $159 \pm 28$ & $264 \pm 42$ & \\
\hline
\end{tabular}

†Sheep term 147 days

$\ddagger$ Acid base values are based on averages \pm standard deviation

§Statistically significant change

IApproximate values read off a graph

(Studies referenced in this table are numbered as appears in Main Text)

10. Luks Fl, Deprest J, Marcus M, et al. Carbon dioxide pneumoamnios causes acidosis in fetal lamb. Fetal Diagn Ther 1994;9:105-9.

11. Pelletier GJ, Srinathan SK, Langer JC. Effects of intraamniotic helium, carbon dioxide, and water on fetal lambs. J Pediatr Surg 1995;30:1155-8.

12. Saiki Y, Litwin DE, Bigras JL, et al. Reducing the deleterious effects of intrauterine CO2 during fetoscopic surgery. J Surg Res 1997;69:51-4.

13. Gratacos E, Wu J, Devlieger R, Van de Velde M, Deprest JA. Effects of amniodistention with carbon dioxide on fetal acid-base status during fetoscopic surgery in a sheep model. Surg Endosc 2001;15:368-72. 


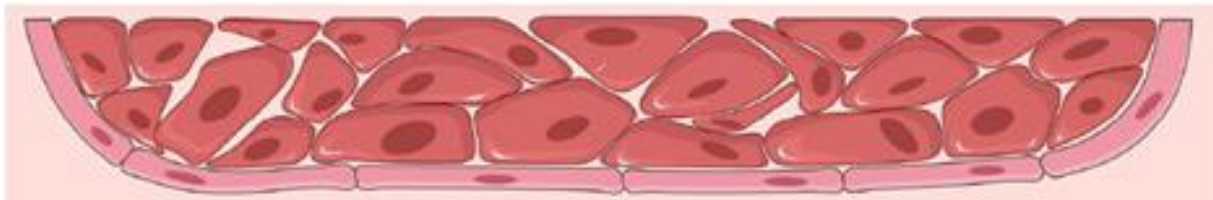

(b) $20 \%$ - binds directly

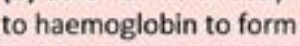
carbaminohaemaglobin

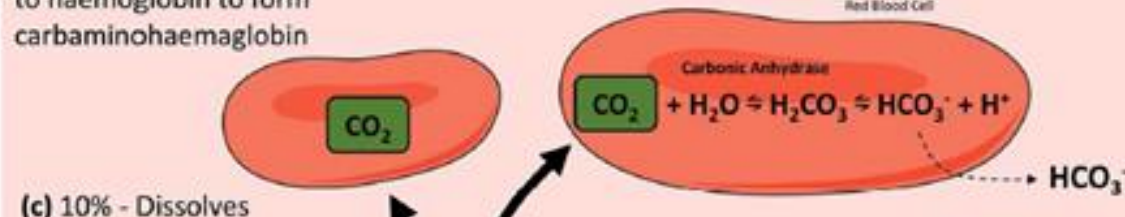
in the plasma

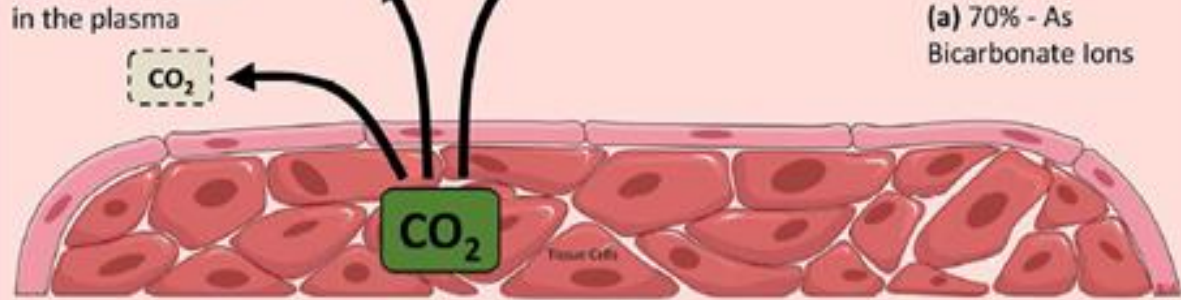

Figure 1

A diagrammatic representation of the how $\mathrm{CO} 2$ produced by active cells is buffered and transported in the plasma. Three pathways (a, b, c) are shown with approximate percentages for each. Pathway (a) represents

the combination of $\mathrm{CO} 2$ and water, catalyzed by carbonic anhydrase within red blood cells, to produce carbonic acid ( $\mathrm{H} 2 \mathrm{CO} 3$ ). Carbonic acid quickly dissociates into hydrogen ions, which bind with deoxygenated hemoglobin, and bicarbonate ions, which diffuse out the cell. Pathways (b) and (c) represent CO2 binding to hemoglobin directly and dissolving plasma respectively. (Schematic by Ben Amberg using Powerpoint Image

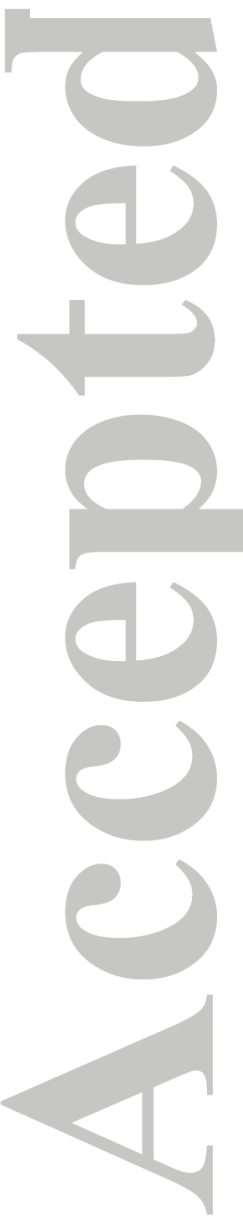

Bank, Servier Medical Art, Servier). 


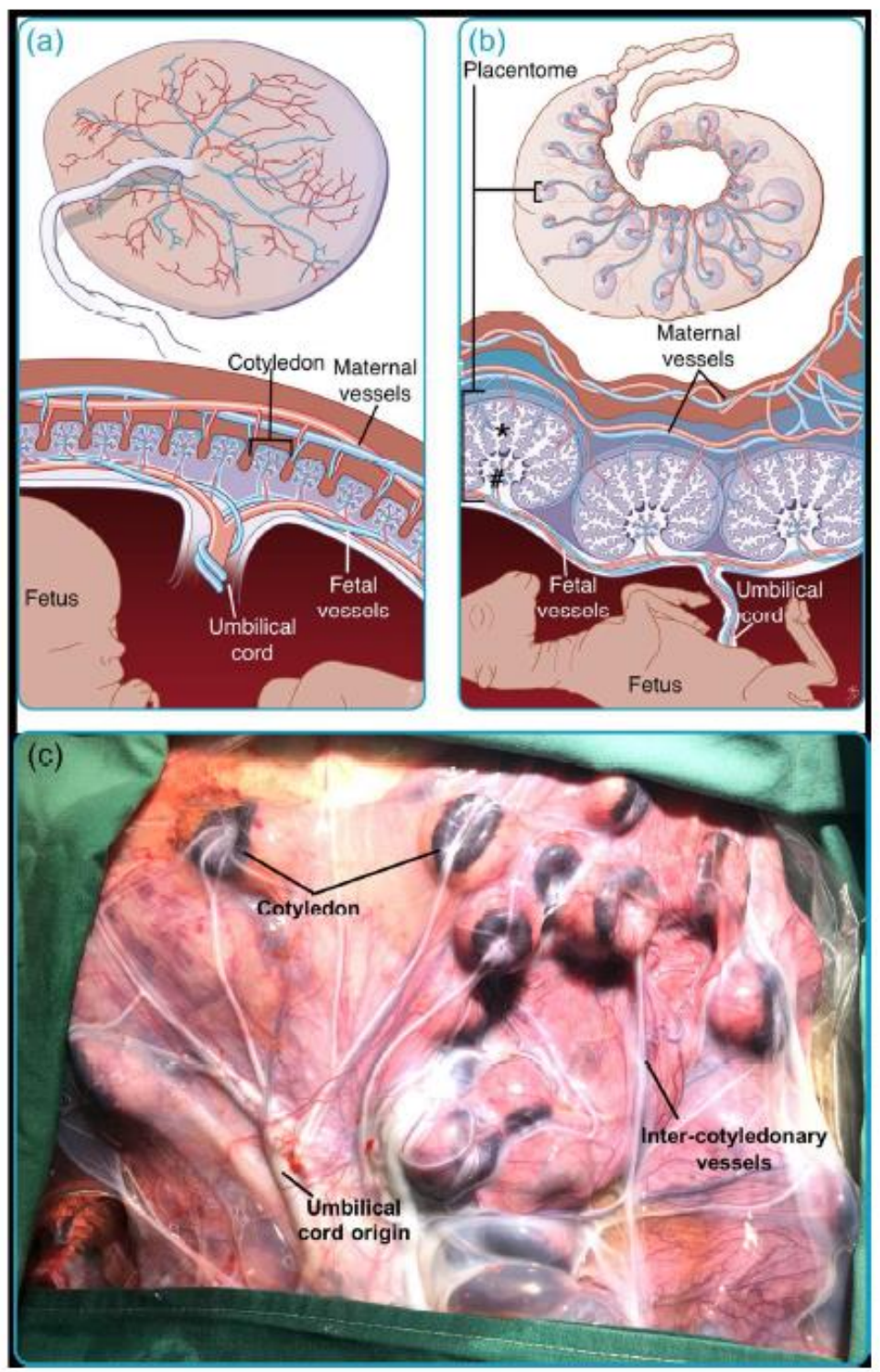

Figure 2

The discoid hemochorial placenta in the humans is diagrammatically represented (a) with maternal blood from uterine spiral arteries bathing fetal chorionic villi containing fetal vessels. The sheep cotyledonary

synepitheliochorial structure is compared (b) with multiple placentomes throughout the uterus. Each placentome is composed of a maternal caruncle $\left(^{*}\right)$ in the uterine wall containing maternal vessels paired with a fetal cotyledon (\#) containing fetal vessels. Fetal cotyledons are joined my inter-cotyledonary fetal vessels that travel through the uterine membranes and coalesce to form the umbilical vessels. The internal aspect of the sheep uterus at postmortem is depicted photographically (c). (Schematic drawings by Myrthe Boymans

(www.myrtheboymans.nl) for, and copyright by, Uz Leuven, Belgium). 